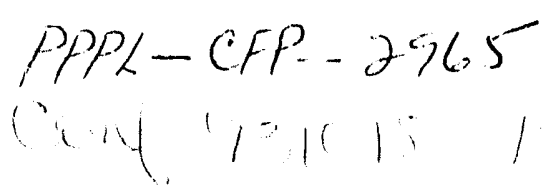

\title{
Special Remote Tooling Developed and Utilized to Tighten TFTR TF Coil Casing Bolts*
}

\author{
T. W. Burgess \\ Oak Ridge National Laboratory, P.O. Box 2008, Oak Ridge, Tennessee 37831-6304 \\ G. R. Walton, T. G. Meighan, and B. L. Paul \\ Princeton Plasma Physics Laboratory, P.O. Box 451, Princeton, New Jersey 08543
}

\begin{abstract}
Special tooling has been developed and used to tighten toroidal field (TF) coil casing bolts that have loosened from years of Tokamak Fusion Test Reactor (TFTR) operation. Duc to their location, many of the TF casing bolts cannot be directly accessed or viewed; their condition was first discovered during unrelated inspections in 1988. Engineering solutions were sought until 1992, when a remotely operated wrench concept was successfully demonstrated on a TF coil mockup. The concept was developed into several working tools that have successfully been applied to tighten several thousand TF casing bolts during recent scheduled outages. This effort has improved the integrity and reliability of the TT coil system in preparing for the final experimental phase of the TFTR. This paper discusses the design and application of this tooling.
\end{abstract}

\section{INTRODUCTION AND BACKGROUND}

\section{A. TF Coil System}

The Tokamak Fusion Test Reactor (TFTR) has 20) toroidal field (TF) coils (see Fig. 1) consisting of wound copper conductors enclosed in a Nitronic 33 casing 11 .

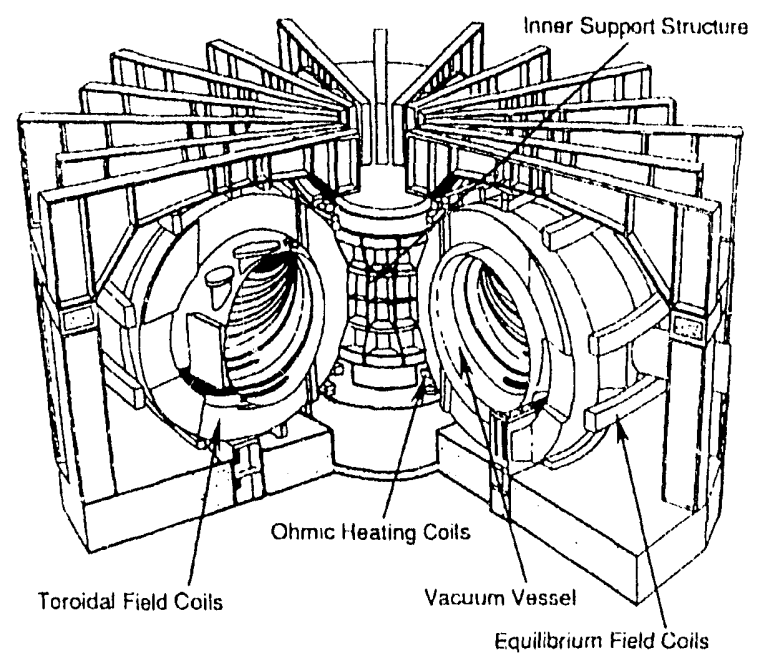

Fig. 1. TFIR magnetic field coils.
Electromechanical forces generated during coil operation are reacted by the casing and transmitted to a system of supports. Each casing assembly is mechanically joined by approximately 1000 bolts distributed around the casing side plates, as shown in Fig. 2. The inner, single row of bolts are $1 \mathrm{in}$., and the outer, double row are $7 / 8 \mathrm{in}$. The bolts are Inconel 718 forgings and were preloaded during initial assembly.

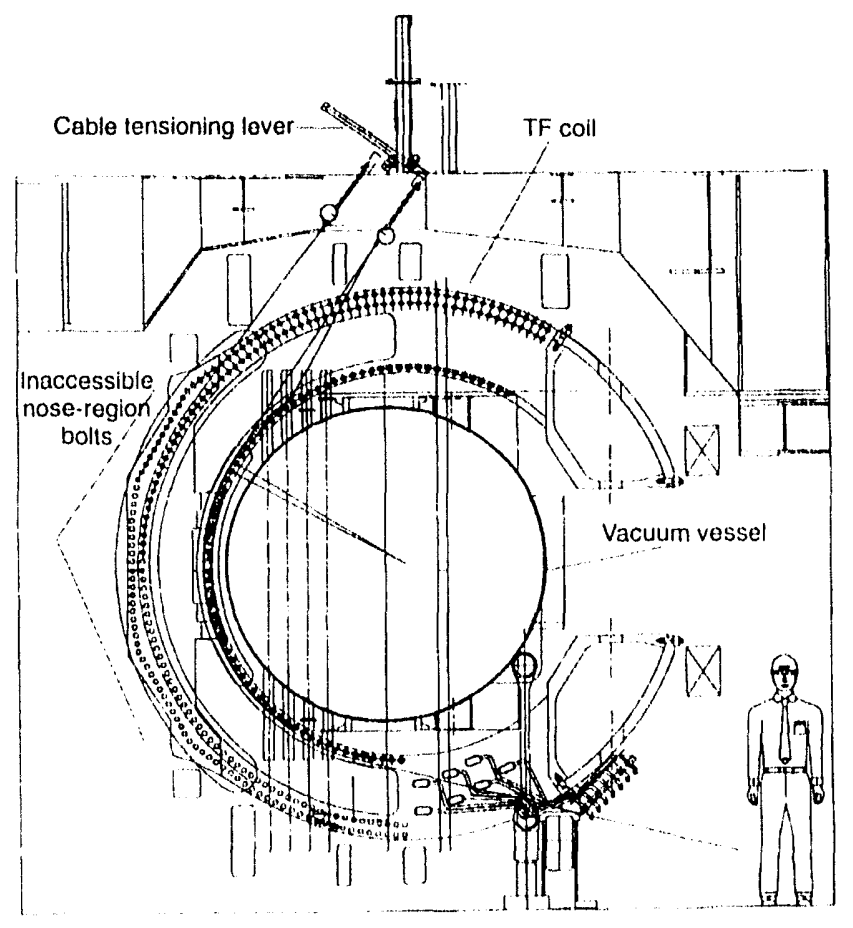

Fig. 2. Tli casing elevation view.

\section{B. Problem}

In 1988, after 5 years of operation, loose bolts were discovered in certain areas of the coil casings. Many of these bolts were located in the coil nose region, towards the inner support structure at the center of the machine. Unfortunately the nose-region bolts, about 252 per coil, cannot be directly accessed or viewed due to their close proximity to adjacent coils and other obstructions such as the vacuum vessel, diagnostic components, and support structures.

\footnotetext{
*Research sponsored by the Office of Fusion Energy, U.S. Department of Energy, under contract DE-ACO5-84OR21400 with Martin Marietta Energy Systems, Inc, and contract DE-ACO2-76CHO3073 with Princelon University.
} 


\section{DISCLAIMER}

This report was prepared as an account of work sponsored by an agency of the United States Government. Neither the United States Government nor any agency thereof, nor any of their employees, makes any warranty, express or implied, or assumes any legal liability or responsibility for the accuracy, completeness, or usefulness of any information, apparatus, product, or process disclosed, or represents that its use would not infringe privately owned rights. Reference herein to any specific commercial product, process, or service by trade name, trademark, manufacturer, or otherwise does not necessarily constitute or imply its endorsement, recommendation, or favoring by the United States Government or any agency thereof. The views and opinions of authors expressed herein do not necessarily state or reflect those of the United States Government or any agency thereof. 


\section{Implications and Solution}

A thorough study of the problem did not yield any definite solutions to the dilemma. The small, curved access passages leading to the bolts, along with many different component obstructions found on the TFTR and the large number of bolts to be tightened, was very constraining. A bolt-tightening device would have to be very compact, time efficient, and capable of negotiating various obstructions in addition to the small passages.

A mechanical analysis of the casing condition showed that the coils could be safely operated close to their design limits and that operation could therefore continue. However, some of the loose bolts had backed away from the casing and were impinging on the dielectric insulation between the coil side plates in 4 of the 20 coil interfaces. The 1/8-in.-thick dielectric layer, an epoxy resin glass (G11), electrically divides the TF coil casings into quadrants to prevent electrical currents in the toroidal direction. TFTR operations could be indefinitely interrupted by electrical shorts in these areas, and some bolts had started to penetrate the dielectric material.

Unique remote tools capable of reaching and manipulating the nose-region bolts were successfully developed and demonstrated on a TF coil mockup in 1992. The t(x)ls were successfully used during the recent scheduled outages to tighten the 1008 bolts in the dielectric regions of the coils. The tools were then used to tighten the remaining $4(0.32$ nose-region bolts to improve the mechanical condition of the entire system.

\section{TOOI.ING; DESCRIP'TION}

Three different tools were developed (see Fig. 3). Lateh is similar in design and operation and differs primarily in the geometry required for the particular boll pattern and size, and in the working space in the channel formed between the coil casing and the diclectric insulation. The shannel at the outer, double row of $7 / 8$-in. bolts lies between the bolts and is rectangular in cross section, (see Fig. 4). It measures approximately 12 by $37 \mathrm{~mm}$ (0.5 by $1.5 \mathrm{in}$.) at the narrowest location and is $3.1 \mathrm{~m}$ (10) fit) long. The channel at the inner, single row of 1 -in. bolts lies 10 the coil side of the bolts, is triangular in cross section and is approximately 12 by $87 \mathrm{~mm}$ (0.5 by $3.4 \mathrm{inl}$ ) at the narrowest locition and is $1.8 \mathrm{~m}(5.8 \mathrm{ft})$ long.

\section{A. Tool Assembly}

Each tool consists of a cable attuated ratcheting wrench mechanism integrated with a small diancter video probe. The key feature of the $(x)$ is the articulated wrench jaw. The jaw is designed (o) (1) deploy 10 and ratchet over a bolt head when the cable is extended and (2) grip the holl to rotate or torque the bolt when the cable is retracted. It provides at positive grip) with minimum contict around the circumference of the bolt head, allowing engagement and disengagement in the spattially restricted environment.

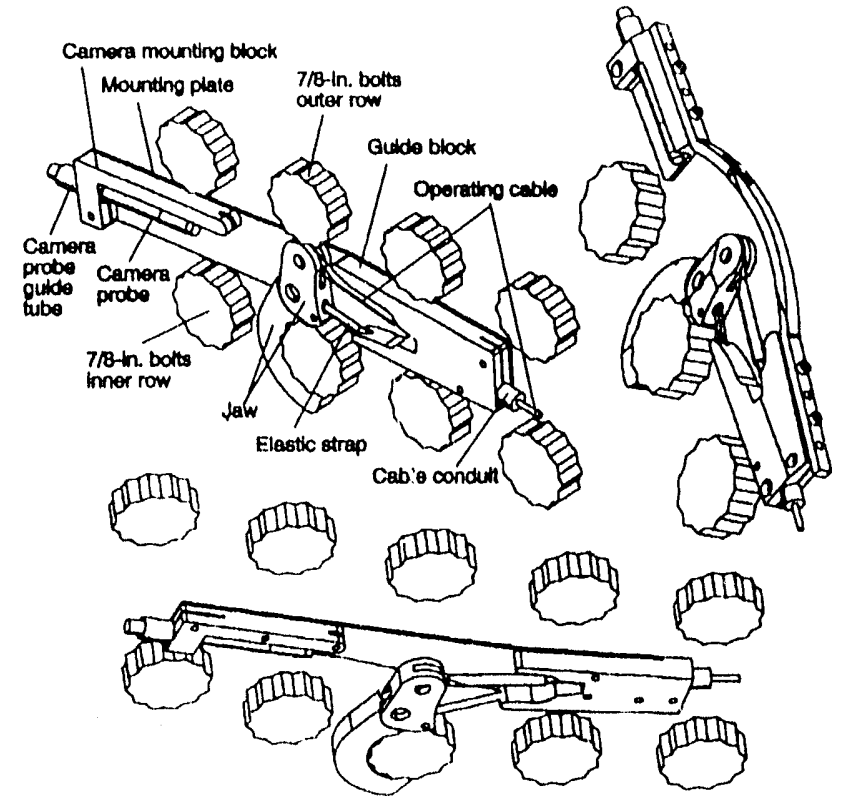

Fïg. 3. TFi casing bolt tool atsemblies: 7/8-in. bolt inner row tool (top lefi), 7/8-in. brilt outer row tool (txottom), 1-in. bolt tool (top right)

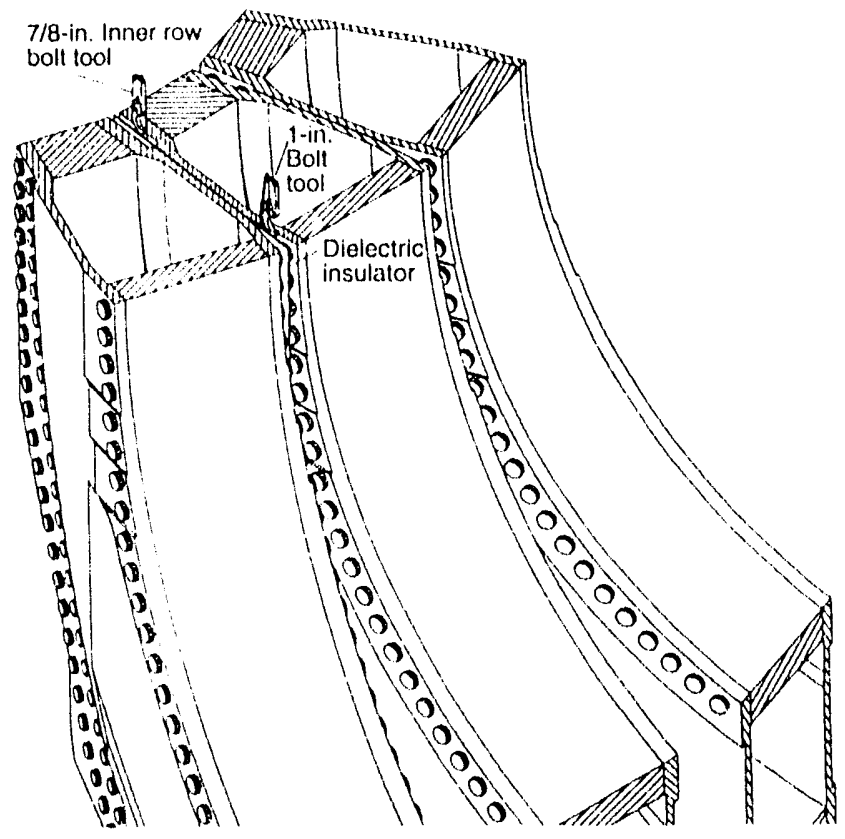

fig. A. Tfi coil cassing sectional view.

The cable is manually operated to grip and snug loose bolts, and is then mechanically tensioned to torgue the bolt.

With the torot assembly positioned in the working channel, the operating cable is extended to deploy the jaw from the assembly to the bolt head, as shown in Fig. 5. The elastic strap attached to the jaw and the alssembly guide bleck caluses the jaw 10 pivol towards the bolt as the cable is extended, regardless of the tosel's orientation to gravity. 

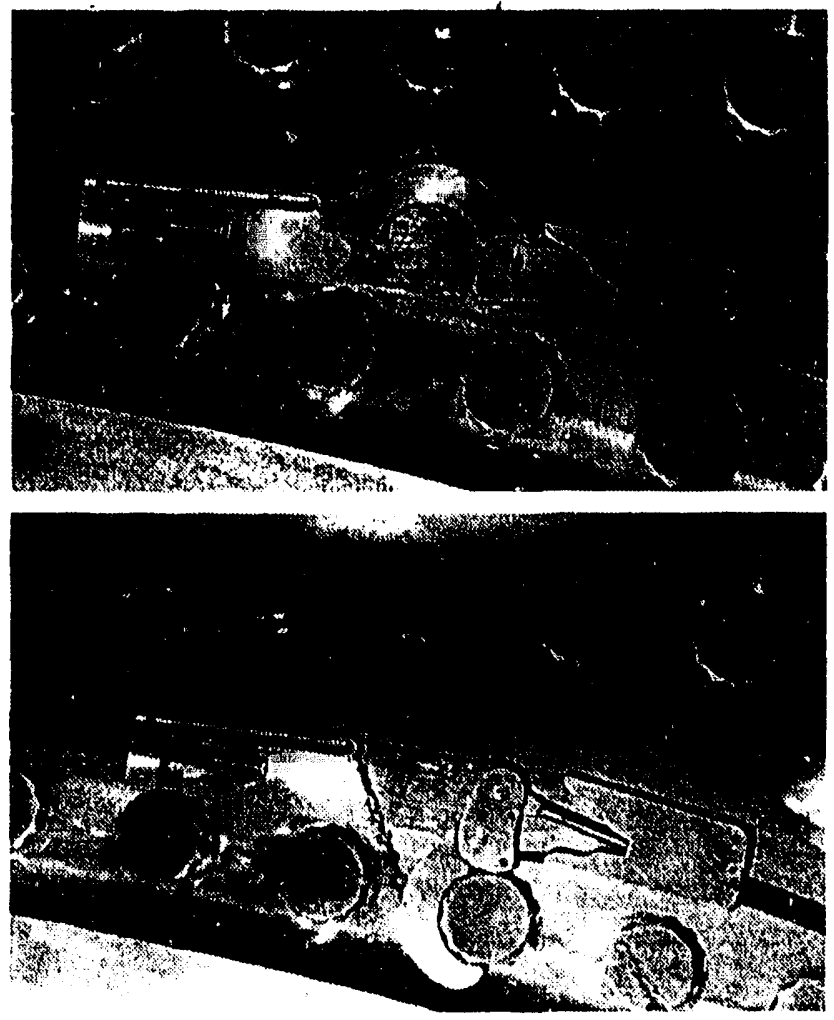

Fig. 5. 7/8-in. inner row boll lool: jaw retracted for tratel in channel (top) and jaw extended to tighten tx)le (bottom:

Through a series of short cable extensions and retrations, a loose. bolt is smugged against the casing, usually in a matter of seconds. The operating cable is then tensioned (1) several hundred pounds to torgue the bolt. Once torepued, the jaw is moved away from the bolt and relrated into the guide block. In this condition, the assembly is fice to move in the channel. The assembly is supported and positioned by the operating cable conduil and/or the video cameral guide lube.

A text is fed and operated from above or below the coil, depending on the bolt configuration and the side of the coil heing worked. For example, the righthatal side 1 in. holts require the torl approach from below, while the lefthand side requires a top-down approach. The viden probe is ted from the opposite end of the channel and thes lwo control areas are involved. Operators condinate their efforts through radio communication.

\section{B. Operating Cable'}

A cable drive was the key fo the tool's flexibility in negotiating obstructions to the Tli coils and the curved paths within the coil channels. Manual operation of the cable was preferred over powered operation becaltse of control simplicity and speed, and the tactile leedback provided to the (operalor.

The size of the cable wats limiled by the working spate in the channels, as was the length of the jaw lever arm. These, in turn, set the maximum torque that conld he produced.

The cable assembly consists of a 2.4 -mm (3/32-in.) stainless steel cable housed in a protective conduit, and equipped with high-strength and fittings and a specially designed T-handle, visible in Fig. 6. The tested ultimate strength of this assembly is 50() $\mathrm{kg}(11(00 / \mathrm{lb})$. All assemblies were load tested to $4(19) \mathrm{kg}(9()() \mathrm{lb})$ and operated at $273 \mathrm{~kg}$ $(600 \mathrm{lb})$ by procedure to minimize the risk of failure. Cables were occasionally tensioned to the test load to free a jammed bolt. Neglecting friction, the 273- to $409-\mathrm{kg}$ cable tension corresponds to a torque output of 14 - to $21 \mathrm{~kg}$-meter (100 to $150 \mathrm{ft}-\mathrm{lb}$ ), which corresponds well with the torque produced on the TF coil mockup.

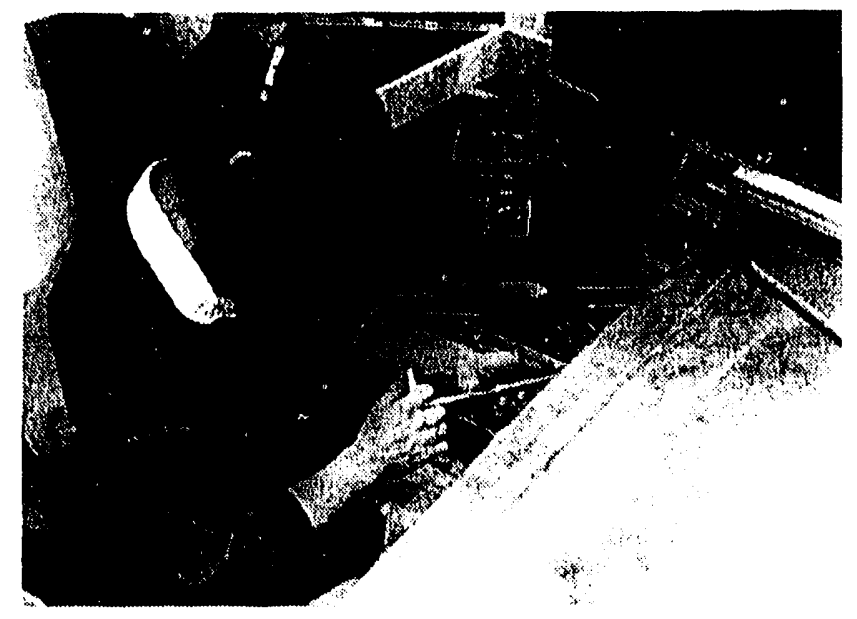

Fig. 6. Manual operation of tool assembly actuating cable during mock-up lest operations.

Various mechanical means were used to tension the cable. Special tensioning fixtures and rigging were designed and fabricated for different areas of TlFT. The sefup generally consisted of either a lever arm or a chain fall, structural support fixtures, and rigging allached directly 10 the 'l-handle with an in-line loald ecll lo indicalle kension. Special cable guide blocks were also fabricalled and used to control the cable rouke and position during tensioning.

The location of the operating stations (above and below the mathine) were dietated by the spate avalable 10 operate and secure the cable tensioning eyuipmiem. (Operating space was very tight, and severall cable lengths were ustally repuired to cover the whole length of a chamnel. For eximple, 4 10 6 different cable lengths were often required when operating the fool from above the machine. Removing the tool to change cables signilicantly delayed the opetatton.

(: Vicuint'

Remote operation of the lowel wats monitored with a (1-mm-diam video probe commercially avialable fromi Welch Allyn. A 10.7-m (3.5-fi) articulated lomg steer probe and Medel VP 2()(o) controller were usied. The probe unilizes a color CCD camera chip integratled wilh a lixed lens and iris, and halogen lighting delivered through hilereptics. Video monitors were located at the two control statioms, as shown during mock-up lesting in lïgs. 6 and 7

The probe wats fed to the tomb assembly through a nylon lube altached to the forl assembly fiom the oppesite end ats the actuating cable. The lube proveded atded profection to the probe and allowed it to be independemly positioned and 
controlled from the tool. As previously noted, the video tube and cable conduit were used to move and position the tool assembly in the bolt channel.

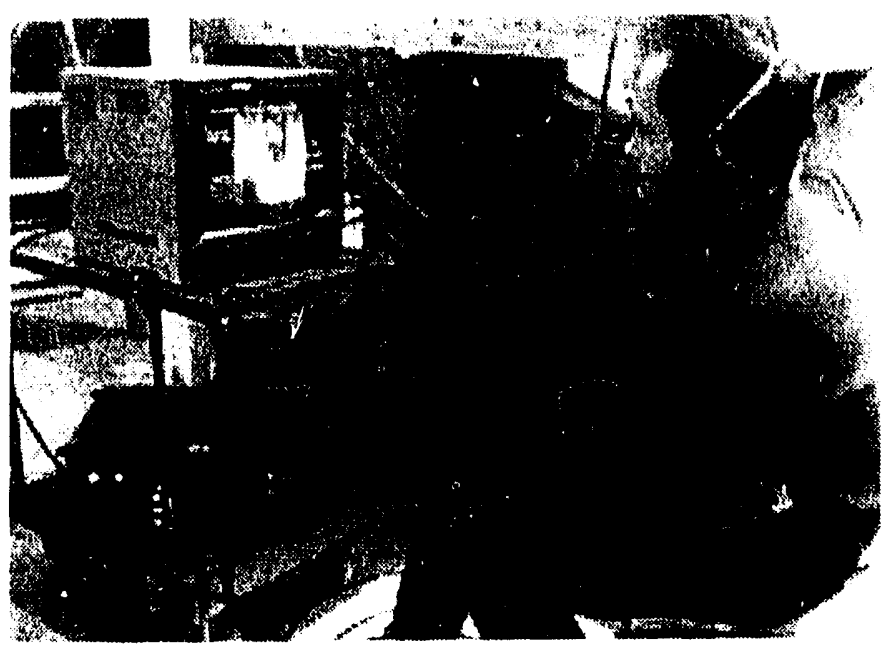

Fig. 7. Video probe camerat control during mock-up lest operations

\section{Tool Materials}

Nonmagnetic materials were used in the tool assembly since the possibility of lodging a tool between coils could not be eliminated. This precluded the use of tool steels in the jaw, which was fabricated from high-strength alloys, A286, and Inconel. The remaining parts of the assembly consisted of 304 stainless steel, 6061 aluminum, and brass.

\section{APPLICATION RESULTS ANIO STATUS}

Two operating crews performed the bolt-lightening operations Each crew consisted of a $(1$; tool assembly operator, (2) cable tensioning equipment operator, (3) video operator, and (4) data collection and general support operator. Data collected included the initial and final condition of each bolt in the inacessible regions. Each crew was equipped with the three different tool assemblies, cable tensioning equipment, and video eyuipment so thall work could be conducted independently.

Bolt-tightening operattons were conducted during two scheduled outage periods, which included many maintenance and modification activities in preparation for the TIFT's final experimental phase: dueterium and tritium (I)T) fueling. The first session of boltefightening operations wats initiated in february and continued through April 1993. The second session was in progress in August and September 1993. The crews worked an extended 1()-h shift, 6 days per week during these periods

\section{A. Dielectric Region Bolts}

The bolts in the dielectric nose regions, 1008 bolls in 2.4 bolt rows, were all torqued in approximately o weeks. (Once proficient with the eyuipment, eiach crew could typically complete one row of bolts per day. Most of his time was required for equipment setup and cable alssembly changes.
Although the condition of the bolts varied widely among coil cases, on the average about $30 \%$ of the bolts were visibly loose. An additional $25 \%$ appeared tight but rotated when torqued, indicating that they were tight to less than $100 \mathrm{ft}-\mathrm{lb}$.

\section{B. Remaining Casing Bolts}

Completing the dielectric region bolts suceessfully demonstrated the tooling and completed the original job scope. The decision was then made to apply the tooling to the bolts in the remaining 16 coil interfaces to improve the mechanical condition of the entire system. The ability 10 tighten bolts in the nondielectric regions had previously been demonstrated on the TF coil mockup. A spacer block wats added to the side of each $t(x) l$ assembly in order to span the wider channel.

A total of 4032 bolts exist in the nose regions of the remaining 16 coil interfaces. The 1 -in. bolts were addressed first because they had the highest percentage of loose bolts. These were completed in approximately 3 weeks and demonstrated the ability to operate the tooling at every coil interface. Special fixtures and cable-routing techniques were required in some locations due to extensive obstructions. The inner row of $7 / 8$-in. bolts was started near the end of the first outage period and then completed in August. The outer row of $7 / 8$-in. bolts was in progress in September with 17 of the 32 bolt rows completed at the time of this writing.

\section{CONCLUDING REMARKS}

The development and application of the remote fooling presented in this paper has helped prepare TTPR for its final phate of operation by improving the structural integrity and reliability of the the coil system. In addition, these improvements are currently being studied to determine if an increatse above the nomal Tl\% coil operating curent can subsequently he applied to maximize fusion perfommance during the final stages of I)T reperation.

\section{ACKNOWIEIOGMNTS}

The authors would like 60 resognize the efforts of the TITR lechnicians who performes the field work during development and application. In particular, we would like to thank the two operating crew leaders, latank l'erlitz and James Walton. We would also like to thank Jack Mount, Mark Kanlik, and liank Polon for their help in keveloping and fabricating the tools and Edward Hill and Richard Yagel for their assistance in many aspects of the project.

\section{REFIRENCE}

11 M. Harmsen el al., "Tokamak Tusion Test Realetun System Description, Si).31), Torroblat fïcld (onls," Rev. 1, PlPl, document, November 1982. 

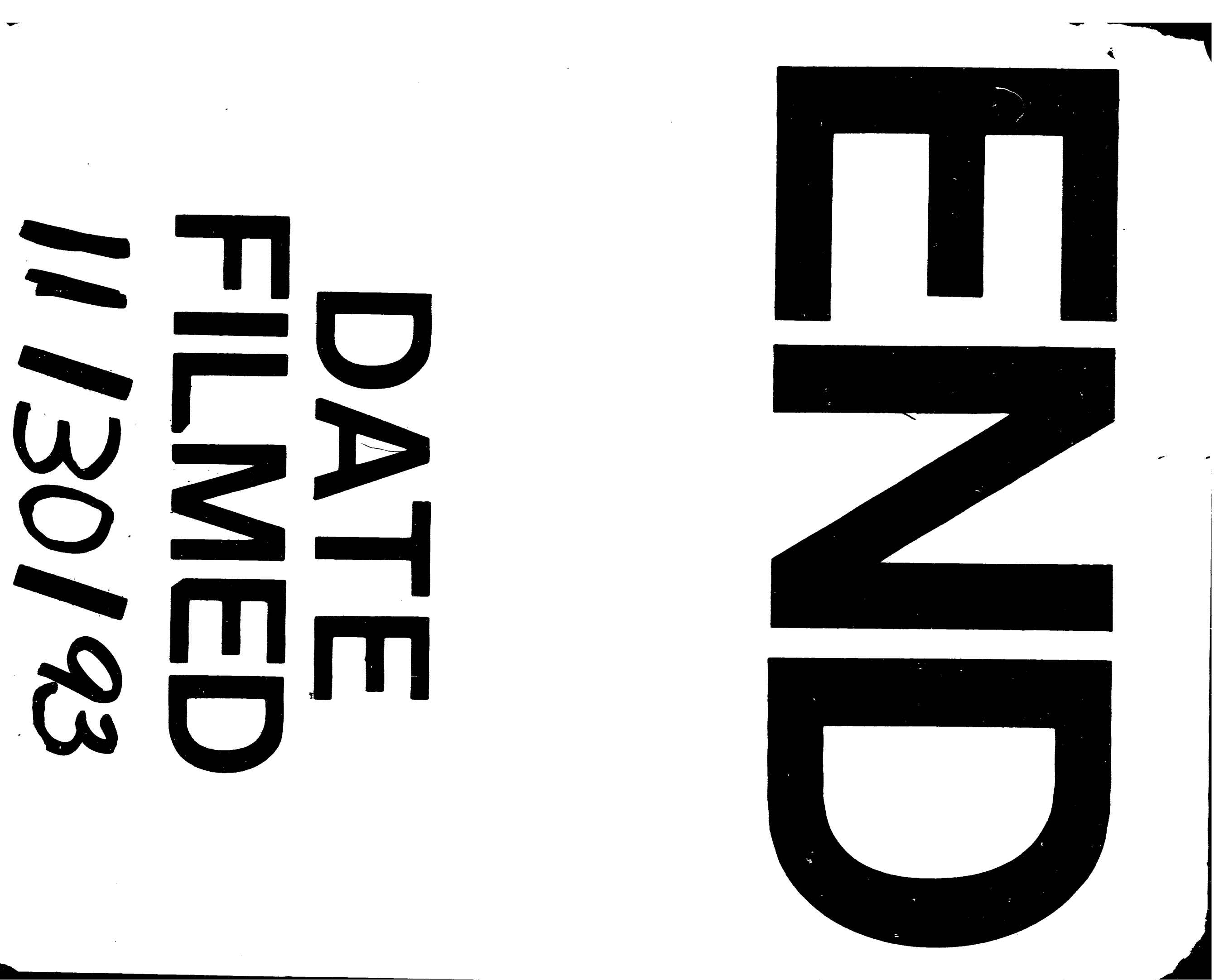
